\title{
Interleukin-15 plays an essential role in the pathogenesis of autoimmune diabetes in the NOD mouse
}

\author{
D. Bobbala • X.-L. Chen • C. Leblanc • M. Mayhue • J. Stankova • \\ T. Tanaka $\cdot$ Y.-G. Chen $\cdot$ S. Ilangumaran $\cdot$ S. Ramanathan
}

Received: 2 May 2012 / Accepted: 5 July 2012 / Published online: 14 August 2012

(C) Springer-Verlag 2012

\begin{abstract}
Aims/hypothesis IL-15, induced by innate immune stimuli, promotes rheumatoid arthritis and inflammatory bowel disease. However, its role in autoimmune type 1 diabetes is unclear. Our aim is to define the role of IL-15 in the pathogenesis of diabetes in the NOD mouse model.

Methods We generated NOD. $I l 15^{-1}$ mice expressing a polyclonal repertoire of $\mathrm{T}$ cell antigen receptor (TCR) or a transgenic TCR and monitored diabetes onset and insulitis. NOD Scid.Ill $5^{-/-}$(full name NOD.CB17-Prkdc scid $/ \mathrm{NCrCrl}$ ) and NOD Scid.gamma (full name NOD.Cg-Prkdc ${ }^{\text {scid }} I l 2 \mathrm{rg}^{\text {tml } I \mathrm{Wjl} /}$ SzJ) mice were used to distinguish the requirement for IL-15 signalling in $\mathrm{CD}^{+} \mathrm{T}$ cells and antigen-presenting cells (APCs) to induce disease. We examined the effect
\end{abstract}

D. Bobbala and X.-L. Chen contributed equally to this work.

Electronic supplementary material The online version of this article (doi:10.1007/s00125-012-2675-1) contains peer-reviewed but unedited supplementary material, which is available to authorised users.

D. Bobbala $\cdot$ X.-L. Chen $\cdot$ C. Leblanc $\cdot$ M. Mayhue $\cdot$ J. Stankova $\cdot$

S. Ilangumaran $\cdot S$. Ramanathan $(\bowtie)$

CRC 4855, Immunology Division, Department of Pediatrics,

Faculty of Medicine and Health Sciences,

3001 North 12th Avenue,

Sherbrooke, Quebec J1H 5N4, Canada

e-mail: Sheela.Ramanathan@Usherbrooke.ca

J. Stankova $\cdot$ S. Ilangumaran $\cdot$ S. Ramanathan

Centre de Recherche Clinique Etienne-Le Bel,

Sherbrooke, Québec, Canada

T. Tanaka

Hyogo University of Health Sciences, School of Pharmacy,

Kobe, Japan

\section{Y.-G. Chen}

Department of Pediatrics, Max McGee National Research Center

for Juvenile Diabetes, Medical College of Wisconsin,

Milwaukee, WI, USA of blocking IL-15 signalling on diabetes onset in NOD mice.

Results At 7 months of age, more than $75 \%$ of the NOD $1115^{-1}$ female mice remained diabetes free compared with only $30 \%$ in the control group. Diabetes incidence was also decreased in 8.3-NOD (full name NOD Cg-Tg[TcraTcrbNY8.3]-1Pesa/ DvsJ).Il15 $5^{-1-}$ mice expressing a highly pathogenic transgenic $\mathrm{TCR}$ on $\mathrm{CD} 8^{+} \mathrm{T}$ cells. Adoptive transfer of splenocytes from diabetic NOD and 8.3-NOD donors induced disease in NOD Scid recipients but not in NOD Scid.Il15 ${ }^{-/-}$or NOD Scid.gamma mice. Transient blockade of IL-15 signalling at the onset of insulitis prevented diabetes in NOD mice.

Conclusions/interpretation Our results show that IL-15 is needed for the initial activation of diabetogenic $\mathrm{CD} 8^{+}$ $\mathrm{T}$ cells as well as for sustaining the diabetogenic potential of antigen-stimulated cells, acting on both $\mathrm{CD} 8^{+} \mathrm{T}$ cells and on APCs. Our findings demonstrate a critical role for IL-15 in the pathogenesis of autoimmune diabetes and suggest that IL-15 is a promising therapeutic target.

Keywords IL-15 - Insulitis · NOD mice · Type 1 diabetes

$\begin{array}{ll}\text { Abbreviations } \\ \text { ALR } & \text { Alloxan resistant } \\ \text { APC } & \text { Antigen-presenting cell } \\ \text { CFSE } & \text { 5-(6)Carboxyfluorescein diacetate succinimidyl ester } \\ \text { CTL } & \text { Cytotoxic T lymphocyte } \\ \text { cDC } & \text { Conventional dendritic cell } \\ \text { DC } & \text { Dendritic cell } \\ \text { HBSS } & \text { Hank's balanced salt solution } \\ \text { IGRP } & \text { Islet-specific glucose-6-phosphatase catalytic } \\ & \text { subunit-related protein } \\ \text { mAb } & \text { Monoclonal antibody } \\ \text { NK } & \text { Natural killer } \\ \text { ROS } & \text { Reactive oxygen species } \\ \text { TCR } & \text { T cell antigen receptor }\end{array}$




\section{Introduction}

IL-15 is induced by innate immune stimuli and type 1 interferons in various cell types, and is required for the development, differentiation and survival of memory $\mathrm{CD} 8^{+}$ $\mathrm{T}$ cells, natural killer (NK), NKT and $\gamma \delta \mathrm{T}$ cells, and certain $T$ cell subsets associated with the mucosal lymphoid tissues [1]. IL-15 also enhances survival of dendritic cells (DCs) and activates DCs and macrophages, and thereby facilitates a robust immune response [2-6]. IL-15 has been implicated in the pathogenesis of certain autoimmune diseases such as rheumatoid arthritis and coeliac disease [7, 8]. However, the contribution of IL-15 to the pathogenesis of autoimmune type 1 diabetes is unclear.

Two studies showed that IL-15 treatment reduced diabetes incidence in the NOD mouse model, suggesting a protective role for IL-15 in type 1 diabetes $[9,10]$. One possible mechanism underlying this observation could be the stimulatory effect of IL-15 on NK cells [11]. However, NK and NKT cells contribute to, or prevent, type 1 diabetes depending on the model studied [12-16]. Regardless of the controversial roles of NK and NKT cells in the pathogenesis of type 1 diabetes, the reported protective effect of IL-15 in type 1 diabetes stands in stark contrast to its pathogenic role in other autoimmune diseases $[7,8]$. Indeed, a pathogenic role for IL-15 in type 1 diabetes is supported by the finding of increased survival of islet grafts in NOD mice following blockade of IL-15 signalling in combination with rapamycin [17]. However, this study did not distinguish the contribution of blocking IL-15 signalling from that of inhibiting the rapamycin targets. Besides, our recent findings in an engineered mouse model of type 1 diabetes implicated a pro-diabetogenic role for IL-15 [18].

To clarify the role of IL-15 in the pathogenesis of type 1 diabetes, we used a genetic approach. We generated NOD $I l 15^{-/-}$mice expressing a polyclonal $\mathrm{T}$ cell antigen receptor (TCR) or a transgenic TCR to study the effect of IL-15 deficiency on diabetes onset, islet infiltration by mononuclear cells and the phenotype and functions of $\mathrm{CD}^{+} \mathrm{T}$ cells. We complemented these studies with adoptive cell transfer experiments, using NOD Scid.Ill $15^{-/-}$and NOD Scid.gamma mice as recipients, and antibody-mediated blockade of IL-15 signalling in NOD mice. Our findings establish a pathogenic role for IL-15 in NOD mice and indicate that IL-15 is a potential immunotherapeutic target in type 1 diabetes.

\section{Methods}

Animals All experiments were carried out under protocols approved by the Université de Sherbrooke Ethics Committee for Animal Care and Use. Mice were housed in micro-isolated sterile cages under specific pathogen-free conditions. NOD (NOD/ShiLtJ), 8.3 TCR transgenic NOD (NOD Cg-Tg[TcraTcrbNY8.3]-1Pesa/DvsJ; 8.3-NOD; for brevity, 8.3-NOD), BDC2.5 TCR transgenic NOD (NOD Cg-Tg[TcraBDC2.5,TcrbBDC2.5]1Doi/DoiJ; for brevity, BDC2.5-NOD], NOD Scid and NOD Scid. gamma (NOD $\left.\mathrm{Cg}-\mathrm{Prkdc}^{\text {scid }} I l 2 \mathrm{rg}^{\mathrm{tml} l \mathrm{Wjl}} / \mathrm{SzJ}\right)$ mice were purchased from the Jackson Laboratory (Bar Harbor, ME, USA). C57BL $/ 61115^{-1}$ mice [11] were obtained from Taconic (Germantown, NY, USA) and backcrossed to NOD background for 11 generations and further backcrossed to 8.3-NOD mice for two generations. At the fifth backcross, mice with known NOD Idd alleles were selected for further breeding. Offspring from the tenth backcross were genotyped for 1,449 SNPs using the Illumina platform (Hospital for Sick Children, Toronto, Canada) to ensure homozygosity of the NOD genetic background. NOD $I l 15^{+/-}$progeny from the 11 th backcross onwards were intercrossed to generate NOD $1 l 15^{-1-}$ mice and NOD $1115^{+/+}$littermates.

Isolation of mononuclear cells from lymph nodes, spleen and pancreatic islets Mononuclear cell suspensions were prepared from pooled lymph nodes, pancreatic lymph nodes or spleen as described previously [18]. Pancreatic islets were isolated following published protocols [19]. In brief, pancreas was digested first in situ by collagenase perfusion, and then ex vivo for an additional $15 \mathrm{~min}$ at $37^{\circ} \mathrm{C}$. Collagenase digestion was stopped by the addition of cold HBSS containing $1 \mathrm{mmol} / 1 \mathrm{CaCl}_{2}$. The dissociated islets were collected by filtration through a 70- $\mu$ m nylon mesh.

Flow cytometry antibodies and flow cytometry reagents (detailed in electronic supplementary material [ESM] Methods) were purchased from BD Pharmingen Biosciences, (Palo Alto, CA, USA) or from eBiosciences (San Diego, CA, USA). Expression of cell surface markers was evaluated by flow cytometry using a FACS Canto flow cytometer (Becton Dickinson, Franklin Lakes, NJ, USA) and the FlowJo software (Tree Star, Ashland, OR, USA).

Cell proliferation and cytotoxic $T$ lymphocyte (CTL) assays Cell proliferation was measured by $\left[{ }^{3} \mathrm{H}\right]$ thymidine incorporation or by evaluating the fluorescence intensity of 5-(6)carboxyfluorescein diacetate succinimidyl ester (CFSE), as detailed in ESM Methods. For the CTL assay, pooled splenocytes and lymph node cells were stimulated with antigen and CTL activity was measured using RMA-S-K ${ }^{\mathrm{d}}$ cells as target cells, as detailed in ESM Methods.

Adoptive transfer, antibody treatment, diabetes monitoring and histopathology Splenocytes from diabetic NOD mice were injected intravenously $\left(10^{7}\right.$ cells) into NOD Scid, NOD Scid. $I l 15^{-1-}$ or NOD Scid. gamma recipients. Female NOD mice were injected intraperitoneally with $200 \mu \mathrm{g}$ of purified TM- $\beta 1$ [20] monoclonal antibody (mAb) or the control 
antibody three times a week, between 4 and 7 weeks of age. Diabetes was monitored using urine glucose strips (Ketodiastix, Bayer, Lerverkusen, Germany). Mice with two consecutive readings of $>3$ (corresponding to $15 \mathrm{mmol} /$ l glucose) were considered diabetic. At the time the mice were killed, pancreases were fixed in buffered formalin and embedded in paraffin. Three non-overlapping (200 $\mu \mathrm{m}$ apart), 5- $\mu \mathrm{m}$ sections were stained with haematoxylin and eosin and blindly scored for insulitis.

Statistical analyses Cumulative incidence of type 1 diabetes was analysed using the Prism software (GraphPad, San Diego, CA, USA). For diabetes incidence, significance was calculated using logrank (Mantel-Cox) Test. For all other variables, significance was calculated by Student's $t$ test.

\section{Results}

IL-15 deficiency protects NOD mice from diabetes Female NOD littermates obtained from intercrossing NOD $I l 15^{+/-}$ mice after the 11th backcross were monitored for diabetes for up to 10 months. As seen in Fig. 1a, NOD $I l 15^{-/-}$mice showed a very significant reduction in diabetes incidence. At 7 months of age, more than $75 \%$ of NOD $1115^{-1-}$ female mice remained diabetes free compared with only $30 \%$ in NOD $1115^{+/+}$littermates and $10 \%$ in the pure NOD colony. Even though nearly $80 \%$ of NOD $I l 15^{-/-}$mice developed discernible insulitis, its severity was significantly reduced in non-diabetic $I l 15^{-/-}$mice compared with $I l 15^{+/+}$littermates (Fig. 1b). Phenotypic analysis of the peripheral $\mathrm{T}$ cell compartment showed a marked reduction in $\mathrm{CD}^{+} \mathrm{T}$ cell frequency and numbers in NOD $1115^{-/-}$mice, and these cells showed reduced expression of the memory cell marker CD44 (Fig. 1c,d,e), as reported in IL-15-deficient C57BL/ 6 mice [11]. The $\mathrm{CD}^{+} \mathrm{T}$ cell compartment was not affected in NOD $1 l 15^{-/-}$mice and the frequency of $\mathrm{CD} 4^{+} \mathrm{CD} 25^{+}$ $\mathrm{T}$ cells was not altered in the pancreatic draining lymph nodes or spleen of IL-15-deficient mice (Fig. 1c, d, e). These results demonstrated a pro-diabetogenic role of IL-15 in the NOD mouse and suggested that the decreased incidence of diabetes in NOD $1 l 15^{--}$mice may arise from impaired activation of diabetogenic $\mathrm{CD} 8^{+} \mathrm{T}$ cells.

IL-15 promotes activation of diabetogenic $C D 8^{+}$Tcells Transgenic 8.3-NOD mice express the highly pathogenic, MHC class-I-restricted 8.3 TCR, which recognises a peptide derived from islet-specific glucose-6-phosphatase catalytic subunit-related protein $\left(\mathrm{IGRP}_{206-214}\right)[21,22]$. In 8.3-NOD mice, 8.3 TCR transgenic $\mathrm{CD} 8^{+} \mathrm{T}$ cells $(8.3$ cells) begin to infiltrate pancreatic islets from 3 weeks of age and become a dominant cell population by 8 weeks [23]. 8.3-NOD female mice develop diabetes between 2 and 3 months of age compared with the 4- to 6-month period required for overt diabetes in non-TCR transgenic NOD mice [21]. To investigate the role of IL-15 on the activation of diabetogenic $\mathrm{CD}^{+} \mathrm{T}$ cells, we generated $8.3-\mathrm{NOD} 1115^{-1-}$ mice and monitored female littermates for diabetes. At 20 weeks of age, only about $50 \%$ of 8.3 -NOD $1115^{-/-}$female mice developed diabetes compared with almost all of the IL-15sufficient littermates (Fig. 2a). Again, insulitis was less severe in non-diabetic 8.3-NOD $1 l 15^{-/-}$mice (Fig. 2b), suggesting that IL-15 may mediate its effects during the early stages of activation of autoreactive $\mathrm{CD} 8^{+} \mathrm{T}$ cells. However, following in-vitro stimulation with IGRP peptide, $\mathrm{CD} 8^{+} \mathrm{T}$ cells purified from 8.3-NOD $1 l 15^{-/-}$mice and 8.3-NOD $I l 15^{+/+}$mice that were equalised for cell numbers showed comparable levels of proliferation and antigen-specific cytolysis of target cells (Fig. 2c,d). Similarly, antigenpresenting cells (APCs) from both IL-15-sufficient and IL15-deficient mice induced proliferation of $8.3 \mathrm{TCR}$ transgenic $\mathrm{CD} 8^{+} \mathrm{T}$ cells with equal efficiency (Fig. 2e). These results indicate that loss of IL-15 does not affect the antigen responsiveness of autoreactive $\mathrm{CD} 8^{+} \mathrm{T}$ cells but impairs their activation in vivo.

Activated diabetogenic T cells continuously require IL-15 to cause disease To determine whether diabetogenic $\mathrm{T}$ cells that are already activated by antigen in vivo still require IL-15 to cause islet destruction, we adoptively transferred total splenocytes from diabetic female NOD mice to NOD Scid and NOD Scid. $I l 15^{-/}$recipients, and monitored them for diabetes. Whereas the NOD Scid recipients developed diabetes within 6 weeks after cell transfer, none of the NOD Scid.Ill15 recipients developed diabetes, even after 8 weeks (Fig. 3a). A majority of islets in NOD Scid.Il15 ${ }^{-1-}$ recipients showed early infiltration and peri-insulitis (Fig. 3b), indicating that islet antigen-specific $\mathrm{T}$ cells had homed to the target organ but were unable to cause disease.

Phenotypic analysis of spleen and lymph node cells from the recipient mice 8 weeks after adoptive transfer showed that the donor cells from diabetic NOD mice had reconstituted the secondary lymphoid organs of both NOD Scid and NOD Scid.Il $15^{-/-}$recipients (Fig. 4a,b). However, the $\mathrm{CD} 8^{+} \mathrm{T}$ cell frequency was severely reduced in the lymph nodes and spleen of NOD Scid.Il15 $5^{-/}$mice, resulting in high CD4/CD8 ratio compared with NOD Scid recipients, and $\mathrm{CD} 8^{+} \mathrm{T}$ cells recovered from NOD Scid.Ill $5^{-1-}$ recipients showed an activated $\left(\mathrm{CD} 44^{\mathrm{hi}} \mathrm{CD} 62^{\mathrm{lo}}\right)$ phenotype (Fig. 4a). To determine whether these $\mathrm{CD} 8^{+} \mathrm{T}$ cells retained their pathogenic potential, we carried out a serial transfer experiment. We pooled splenocytes from the non-diabetic NOD Scid.Ill15 ${ }^{-/-}$recipients and adoptively transferred to a next batch of NOD Scid recipients. While splenocytes from diabetic NOD Scid mice induced diabetes in the second batch of NOD Scid recipients within 3-4 weeks, splenocytes 
Fig. 1 Genetic ablation of the Ill 15 gene prevents type 1 diabetes in the NOD mouse. (a) $I l 15^{-/-}$(black circles, $n=26$ ) and $I l 15^{+/+}$(black triangles, $n=20$ ) female NOD littermates were monitored for the development of type 1 diabetes. For comparison, diabetes incidence in a pure NOD colony is shown (white inverted triangles, $n=31)$. ${ }^{* * *} p<0.001$ (logrank test). (b) Pancreatic sections from three-five 4-month-old $I l 15^{-/}$and $I l 15^{+/+}$ NOD mice were evaluated and scored for insulitis: no insulitis (white), early infiltration (light grey), peri-insulitis (dotted), invasive (dark grey) or end stage (black). Representative sections from mice of each genotype are shown. (c, d) Mononuclear cells from pooled inguinal, brachial, cervical and pancreatic lymph nodes (black and dotted) and spleen (white and grey) from age-matched NOD $1 / 15^{+/+}$(black and white) and NOD $1115^{-1-}$ (dotted and grey) female mice were analysed for the frequency of $\mathrm{CD}^{+}$and $\mathrm{CD}^{+} \mathrm{T}$ cells, and $(\mathbf{e}, \mathbf{f})$ expression of CD44 and CD25. Representative data from at least three mice for each genotype are shown. (e) The absolute cell numbers were calculated from data pooled from five mice for each genotype. $* * * p<0.001$ (Student's $t$ test). Error bars represent the SEM
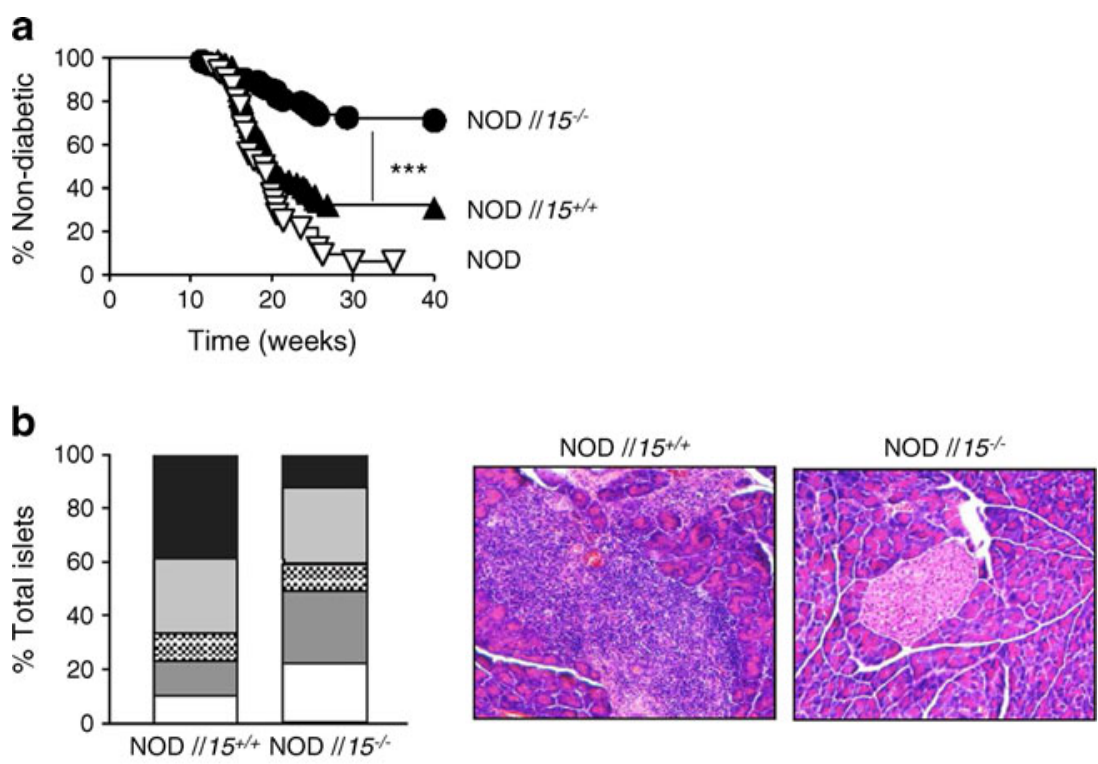

C
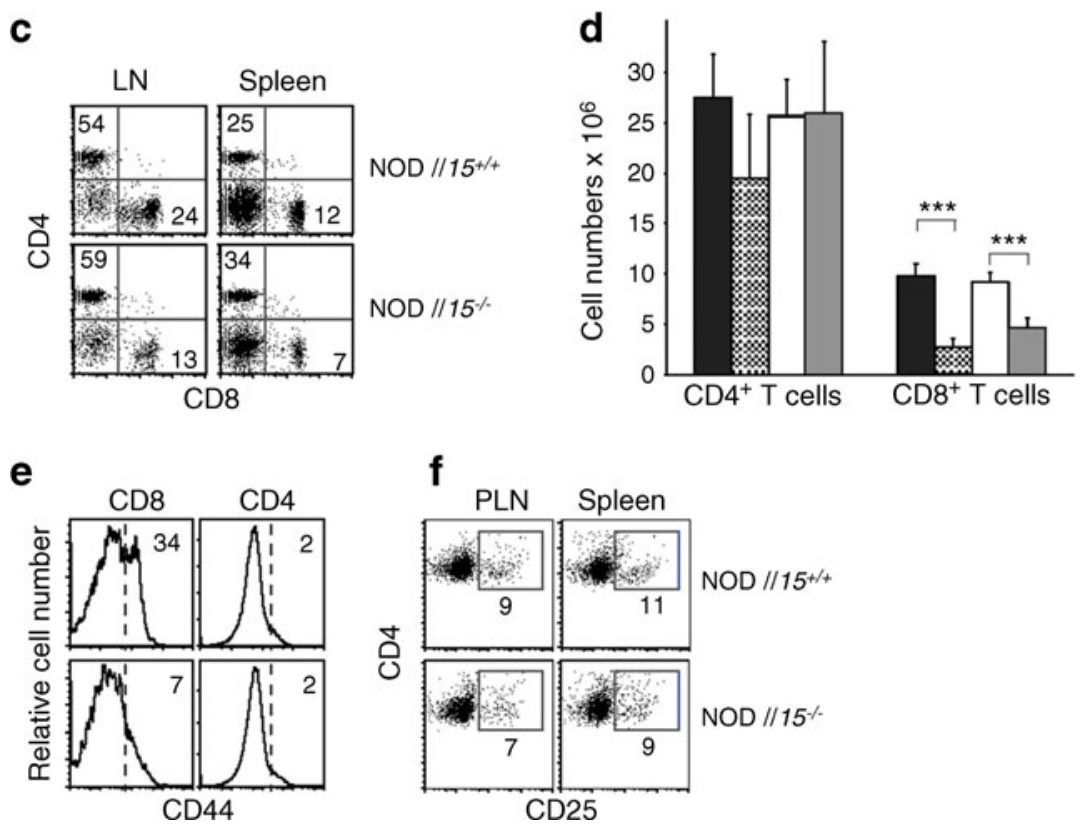

obtained from the non-diabetic NOD Scid.Il15 ${ }^{-/}$recipients did not become diabetic even after 8 weeks (Fig. 4c). These results suggest that IL-15 is continuously required to sustain the pathogenic potential of antigen-stimulated diabetogenic $\mathrm{T}$ cells, which could arise from a direct effect of IL-15 on CD8 T cells, modulation of APC functions by IL-15, or both.

IL-15 is required to maintain the survival of diabetogenic effector $C D 8^{+}$Tcells As IL-15 signalling is essential for the survival of memory $\mathrm{CD} 8^{+} \mathrm{T}$ cells in the periphery $[11,24]$, the inability of diabetogenic NOD T cells to cause disease in NOD Scid.Il15 $5^{-1-}$ recipients may result from the loss of islet-specific $\mathrm{CD}^{+} \mathrm{T}$ cells from the pool of surviving T cells in NOD Scid.Ill $5^{-/-}$mice. To facilitate the tracking of islet antigen-specific $\mathrm{T}$ cells, we used TCR transgenic $\mathrm{T}$ cells specific to MHC-I- or MHC-II-restricted peptides derived from islet antigens, instead of polyclonal $\mathrm{T}$ cells from diabetic NOD mice (shown in Fig. 3), in adoptive transfer experiments. As shown in Fig. 5a, splenocytes from diabetogenic mice expressing the MHC-I-restricted 8.3 transgenic TCR were unable to induce diabetes following adoptive transfer to NOD Scid.Ill15 $5^{-1}$ recipients, but caused disease in NOD Scid mice. The inability of these cells to induce diabetes in NOD Scid.Ill15 ${ }^{-/-}$recipients did not arise from decreased susceptibility of their islets to immune destruction because these mice developed diabetes following adoptive transfer of splenocytes from MHC class-II restricted TCR transgenic BDC2.5 mice (Fig. 5b). Phenotypic analysis of the mononuclear cells of spleen and lymph nodes of the 
a
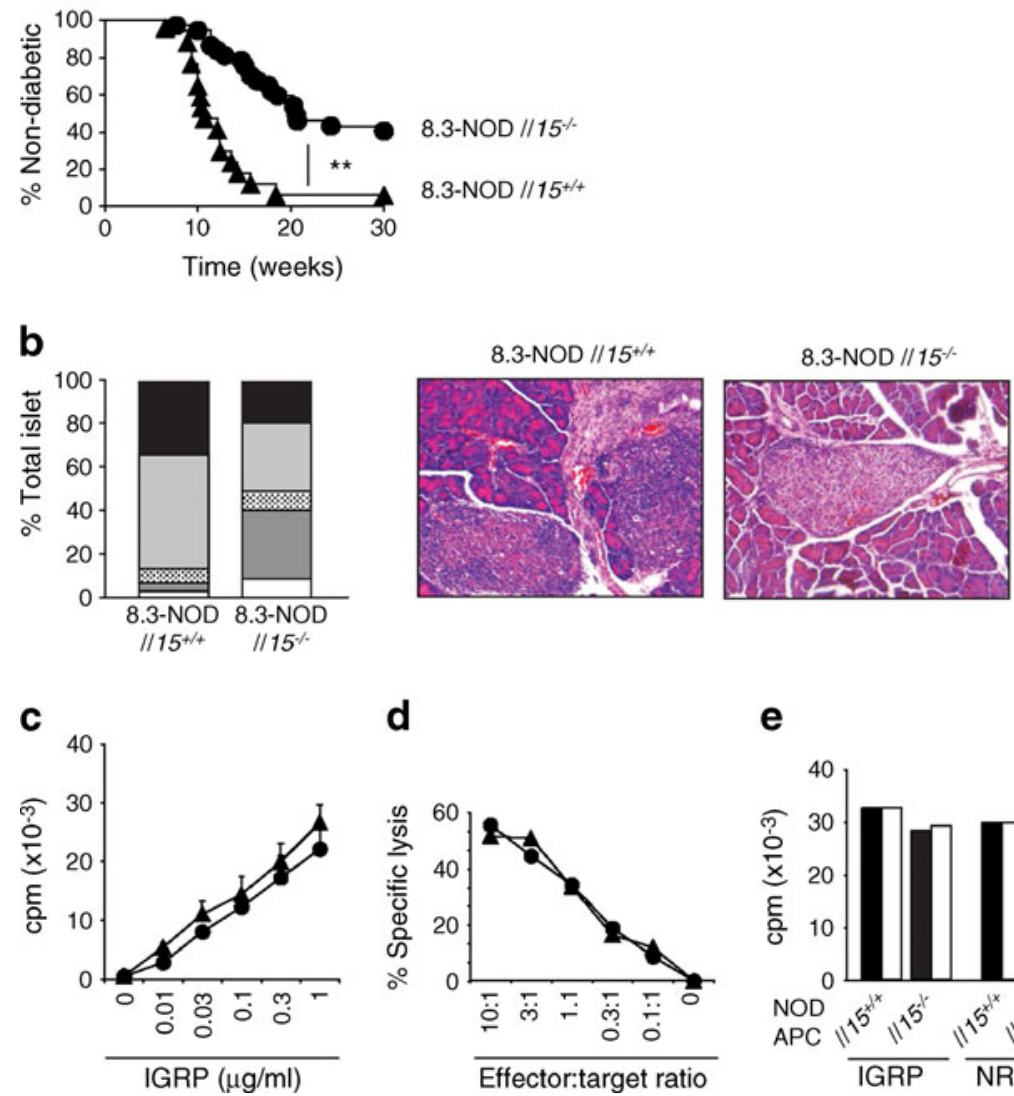

d
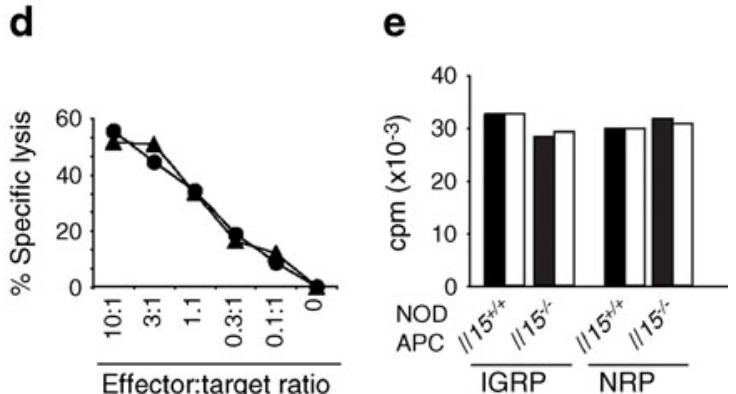

Fig. 2 Loss of IL-15 prevents type 1 diabetes in 8.3 TCR transgenic NOD mice. (a) $I l 15^{-/-}$(circles, $n=22$ ) and $I l 15^{+/+}$(triangles, $n=13$ ) female 8.3-NOD littermates, expressing the highly pathogenic MHC class-I-restricted 8.3 transgenic TCR, were monitored for diabetes development. ${ }^{* *} p<0.01$ (logrank test). (b) Pancreatic sections from representative $I l 15^{-/-}$and $I l 15^{+/+}$8.3-NOD mice at 2 months of age were evaluated for insulitis and scored as detailed in Fig. 1b. Representative sections from mice of each genotype are shown. (c, d) Purified 8.3 TCR transgenic $\mathrm{CD}^{+} \mathrm{T}$ cells of from $I l 15^{+/+}$(circles) and $1115^{-/-}$(triangles) 8.3-NOD female mice were activated with the cognate peptide

recipient mice showed that the frequency of 8.3 TCR transgenic donor $\mathrm{CD} 8^{+} \mathrm{T}$ cells decreased in NOD Scid.Ill15 ${ }^{-/}$ recipients 1 month after cell transfer (Fig. 5c), although their proliferation in response to the IGRP peptide was comparable with that of cells recovered from NOD Scid recipients (Fig. 5d). However, these cells became almost undetectable in NOD Scid.Ill15 $5^{-/-}$recipients 2 months after transfer (Fig. 5e). These results suggest that IL-15 is required to maintain the survival of antigen-stimulated diabetogenic $\mathrm{CD} 8^{+} \mathrm{T}$ cells.

IL-15 signalling in APCs is required to maintain pathogenic potential of diabetogenic $T$ cells As IL-15 is known to modulate the functions of DCs $[2,3,5,6]$, it is possible that the lack of IL-15 in NOD Scid.Il15 $5^{-/-}$mice may also affect the ability of APCs to provide stimulatory signals that may be required to maintain their prolonged survival and renewal. To
IGRP $_{206-214}$ in the presence of irradiated NOD splenocytes as APCs. (c) Cell proliferation was measured by adding $\left[{ }^{3} \mathrm{H}\right]$ thymidine for the last $12 \mathrm{~h}$ of the culture period. Error bars represent the SEM. (d) CTL assay was carried out using RMA-S.K ${ }^{\mathrm{d}}$ cells pulsed with NRP-V7 peptide as target cells. Error bars represent the SEM. (e) $8.3 \mathrm{CD} 8^{+} \mathrm{T}$ cells purified from $I l 15^{+/+}$(black bars) and $I l 15^{-/}$(white bars) 8.3-NOD mice were activated with $1 \mu \mathrm{g} / \mathrm{ml} \mathrm{IGRP}{ }_{206-214}$ peptide, or the mimotope NRP, in the presence of irradiated NOD $I l 15^{-/-}$and NOD $I l 15^{+/+}$splenocytes as APCs. Representative data from three (d) or two (e) independent experiments with similar results are shown

address this issue, we used NOD Scid.gamma mice as recipients of diabetogenic T cells. The NOD Scid.gamma mice express and trans-present IL-15, but do not express the $\gamma_{\mathrm{c}}$ chain (CD132) of the IL-15 receptor complex. Hence, their own APCs cannot respond to endogenously produced IL-15, or other $\gamma_{c}$ cytokines, whereas donor T cells with intact IL-15 receptor complex can. We observed that both polyclonal and 8.3 TCR transgenic T cells from diabetic donors, which induced disease in NOD Scid recipients, failed to induce diabetes in NOD Scid.gamma recipients as in NOD Scid.Il15 $5^{-1-}$ recipients (Figs 3a, 5a). However, the NOD Scid.gamma recipients sustained the survival of donor 8.3 TCR transgenic $\mathrm{CD}^{+} \mathrm{T}$ cells better than in NOD Scid.Il15 ${ }^{-1-}$ mice or even NOD Scid recipients (Fig. 5c, top and middle rows), presumably due to increased availability of IL-15 resulting from the lack of its use caused by $\gamma_{\mathrm{c}}$ deficiency. Besides, adoptively transferred polyclonal $\mathrm{T}$ cells recovered from 

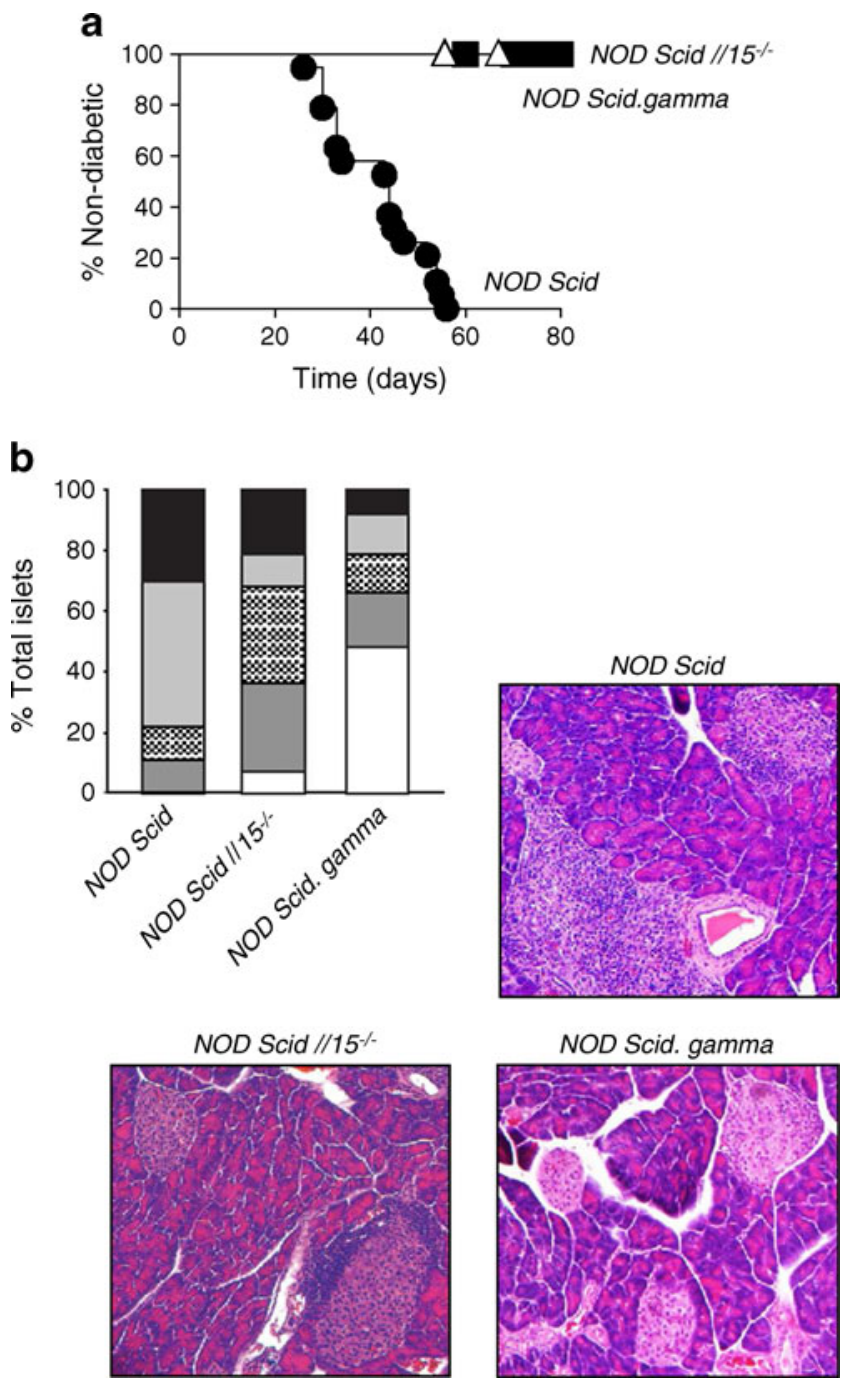

Fig. 3 Diabetogenic T cells do not cause disease in NOD Scid mice lacking IL-15. (a) Total splenocytes from clinically diabetic female NOD mice expressing a polyclonal TCR repertoire were injected intravenously $\left(1 \times 10^{7}\right.$ cells) into NOD Scid (black circles, $\left.n=16\right)$, NOD Scid.Il15 ${ }^{-1-}$ (black squares, $n=18$ ) or NOD Scid.gamma (white triangles, $n=11$ ) recipients and diabetes was monitored. Cumulative incidence of diabetes is shown. Some of the NOD Scid. $1115^{-/}$and NOD Scid.gamma recipients were killed 60-80 days after adoptive transfer to recover the donor $\mathrm{T}$ cells for phenotype analysis and serial transfer experiments shown in Fig. 4. (b) Pancreatic sections from the recipient mice of each genotype were scored for insulitis as detailed in Fig. 1b. Representative sections from mice of each genotype are shown

NOD Scid.gamma recipients showed a normal CD4/CD8 ratio, as in NOD Scid recipients, and the $\mathrm{CD}^{+} \mathrm{T}$ cells showed a CD44 ${ }^{\text {hi }} \mathrm{CD} 62^{\text {hi }}$ phenotype (Fig. 4b). Even though these cells failed to induce diabetes and showed reduced ability to cause insulitis in NOD Scid.gamma recipients (Fig. 3), they retained their pathogenic potential as they could cause diabetes upon subsequent transfer to NOD Scid mice (Fig. 4b). These findings suggest that IL-15 signalling in APCs is dispensable for the survival of diabetogenic $\mathrm{T}$ cells, but is critical for APCs to provide antigenic and/ or non-antigenic stimulation necessary to elicit the pathogenic potential of diabetogenic $\mathrm{T}$ cells.

Transient blockade of IL-15 signalling during the preinsulitis stage delays type 1 diabetes Given the importance of IL-15 signalling in both CD8 T cells and APCs to sustain the pathogenic potential of diabetogenic T cells, as indicated by the above experiments, we tested whether inhibition of IL-15 signalling would hinder the pathogenic process in type 1 diabetes. For this purpose, we used the TM- $\beta 1$ $\mathrm{mAb}$ directed against the IL-2/15R $\beta$ chain, which inhibits IL-15 receptor signalling without interfering with IL-2 receptor signalling $[20,25,26]$. TM- $\beta 1$ was previously shown to prevent pathology in a mouse model of coeliac disease [27]. To address the effect of blocking IL-15 signalling in type 1 diabetes, we administered TM- $\beta 1$ or control $\mathrm{mAb}$, to NOD mice three times a week between 4 and 7 weeks of age. As shown in Fig. 6a, treatment with control mAb did not alter diabetes incidence, whereas TM- $\beta 1 \mathrm{mAb}$ significantly delayed diabetes development. Furthermore, TM- $\beta 1$ treated mice that did not develop diabetes showed markedly reduced insulitis (Fig. 6b). These results indicate that IL-15 is a potential target for immunotherapeutic intervention of type 1 diabetes.

\section{Discussion}

The results presented in this study establish a pathogenic role for IL-15 in autoimmune type 1 diabetes. In other autoimmune diseases, such as rheumatoid arthritis and inflammatory bowel disease, IL-15 is implicated in the activation of $\mathrm{CD}^{+} \mathrm{T}$ cells, which in turn perpetuate the autoimmune inflammatory process $[7,8]$. Our findings implicate IL-15 not only in promoting the activation, survival and maintenance of diabetogenic $\mathrm{CD}^{+} \mathrm{T}$ cells but also in facilitating the pathogenic role of APCs.

The $I l 15$ gene is located on chromosome 8 at $39.33 \mathrm{cM}$, near the $I d d 22$ locus at $43.06 \mathrm{cM}$, which harbours certain disease-protective genes [28]. The Idd22 locus lies in close proximity to antioxidant genes linked to protection of islets from damage caused by reactive oxygen species (ROS) in the Alloxan resistant (ALR) strain, and as yet uncharacterised genes in the $129 \mathrm{~S} 1 / \mathrm{Sv}$ strain $[28,29]$. This raises the possibility that decreased incidence of diabetes in NOD Scid. $1115^{-/-}$ mice may arise from perturbation of the Idd22 locus via introduction of the $I l 15$ null allele from the C57BL/6 strain. However, this possibility is unlikely for various reasons. First, genetic crosses between C57BL/6 and NOD strains identified the $I d d 3$ and $I d d 10$ loci, while these studies reported no linkage to chromosome 8 that harbours the Idd22 locus [30]. Moreover, resistance to ROS-induced islet damage is unique to the ALR strain, and was not observed in the C57BL/6 strain 

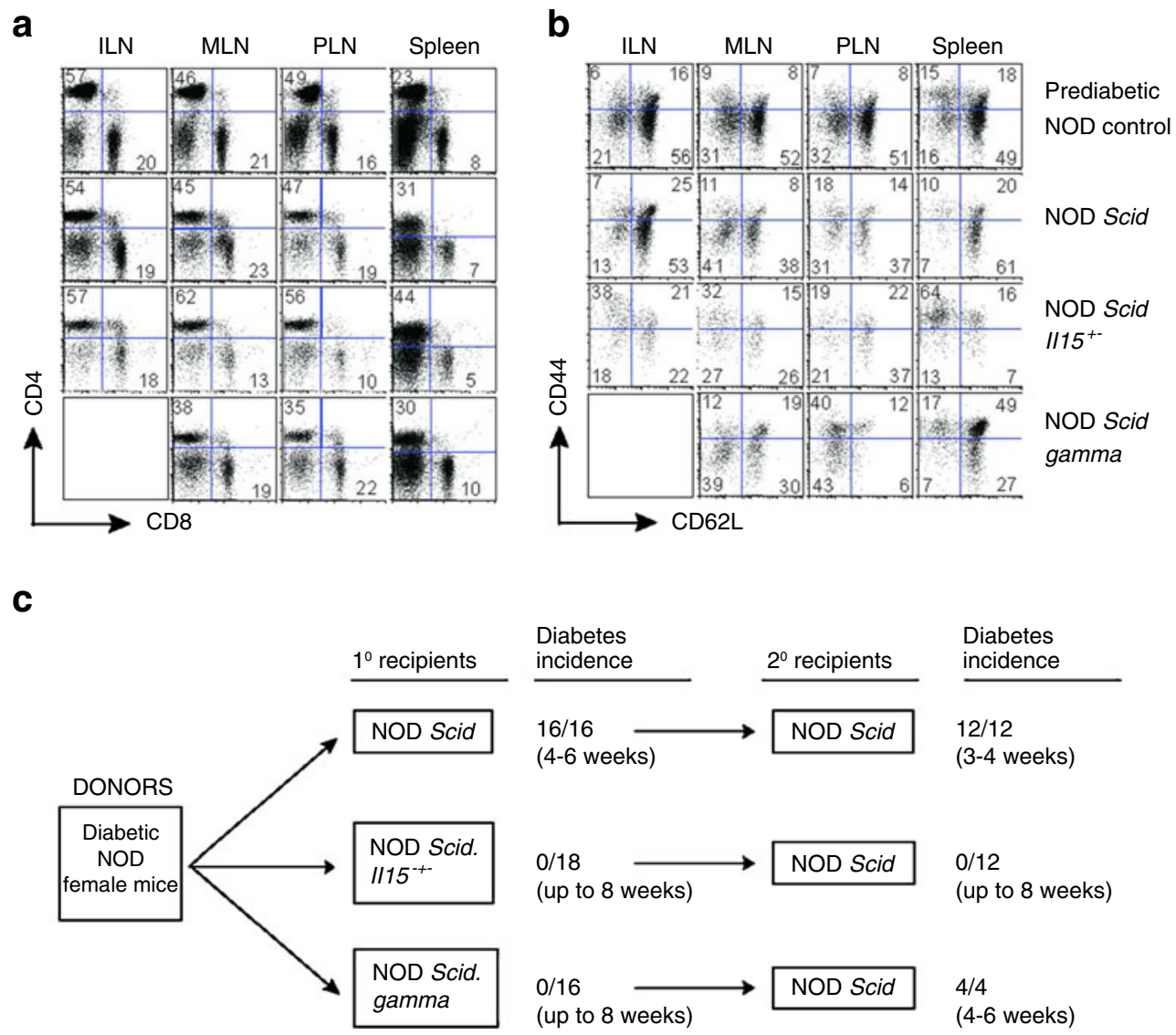

Fig. 4 Activated diabetogenic T cells continuously require IL-15 to retain their pathogenic potential. Total splenocytes from diabetic female NOD mice expressing a polyclonal TCR repertoire were injected intravenously $\left(1 \times 10^{7}\right.$ cells $)$ into NOD Scid, NOD Scid.Il $15^{-/-}$or NOD Scid.gamma recipients as in Fig. 3a. When the NOD Scid recipients developed diabetes, representative mice from each recipient group were killed. (a,b) Cell suspensions from inguinal (ILN), mesenteric (MLN) and pancreatic (PLN) lymph nodes and spleen were separately analysed by flow cytometry to determine the proportion of $\mathrm{CD}^{+}$and $\mathrm{CD}^{+} \mathrm{T}$ cells $(\mathbf{a})$, and the frequency of cells expressing CD44 and CD62L (b) within the $\mathrm{CD} 8^{+} \mathrm{T}$ cell subset. Numbers within the quadrants indicate the proportion of cells corresponding to the phenotype. Representative data from one mouse for each recipient group, from at

$[28,31]$, whose embryonic stem cells were used to generate the Il15 null allele [11]. Second, similar to NOD Scid.Il15 ${ }^{-1-}$ recipients, NOD Scid.gamma recipients do not develop diabetes following transfer of splenocytes from diabetic NOD mice. The gene coding for the $\gamma_{c}$ chain is located on the $\mathrm{X}$ chromosome, which does not harbour any known Idd locus [32]. Third, $\mathrm{CD}^{+} \mathrm{T}$ cells expressing the BDC2.5 transgenic TCR induce diabetes in NOD Scid recipients via production of cytokines and soluble mediators, which induce ROS that cause islet destruction [33, 34]. Diabetes induction by BDC2.5T cells in NOD Scid recipients was not affected by IL-15 deficiency, indicating that the $I 115^{-/-}$allele does not compromise the sensitivity of the NOD Scid.Il15 $5^{-1-}$ islets to oxidative damage (Fig. 5b). Fourth, inhibition of IL-15 least two independent experiments with five or six mice per group of recipients, are shown. ILN from NOD Scid.gamma recipients were too small to be analysed (blank square). For comparison, cells from prediabetic NOD mice are shown (top row). (c) When the NOD Scid recipients developed diabetes, total splenocytes $\left(1 \times 10^{7}\right.$ cells $)$ from NOD Scid, NOD Scid.Ill $5^{-1-}$ or NOD Scid.gamma recipients $\left(1^{\circ}\right.$ recipients) were serially transferred to a next batch of NOD Scid recipients $\left(2^{\circ}\right.$ recipients), which were monitored for diabetes onset. For each group of recipients, the number of mice used (denominator) and those that developed diabetes (numerator), and the time taken for diabetes development or the duration of observation in the case of no disease are indicated

signalling in NOD mice harbouring the unperturbed Idd 22 locus significantly reduces diabetes incidence and disease severity (Fig. 6). Fifth, we have shown that IL-15 deficiency also affects diabetes induction in a TCR transgenic model of type 1 diabetes in the C57BL/6 background [18]. Sixth, a recent report has shown that NOD mice express a reduced level of $\mathrm{Il}-15$ transcripts when compared with $\mathrm{C} 57 \mathrm{BL} / 6$ mice and that increasing IL-15 bioavailability induces diabetes in $30 \%$ of $\mathrm{BDC} 2.5 \mathrm{TCR}$ transgenic mice, which do not develop spontaneous diabetes [35]. Again this suggests a pathogenic role for IL-15. Seventh, reports on increased expression of IL-15 in NOD islets upon ageing and upregulation of IL-15 in rat and human islets treated with IFN- $\gamma$ implicate IL-15 in the pathogenesis of type 


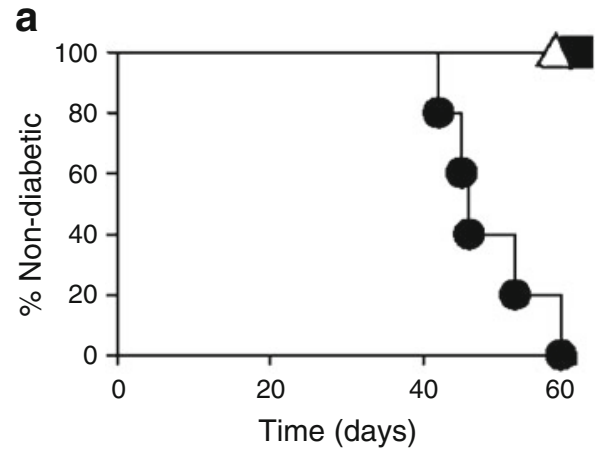

C
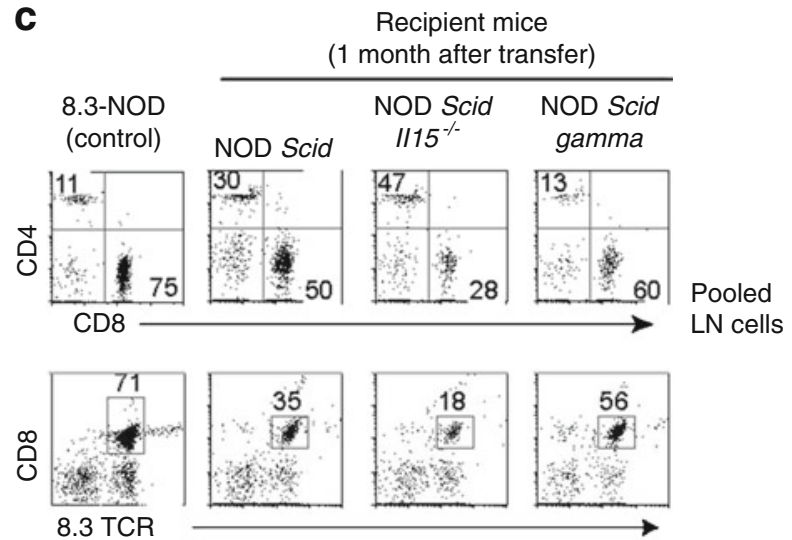

d

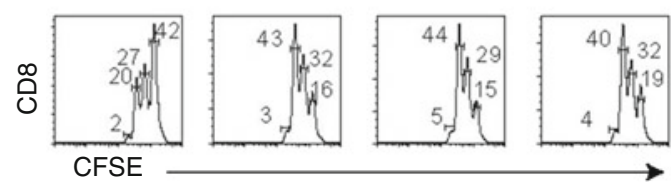

b

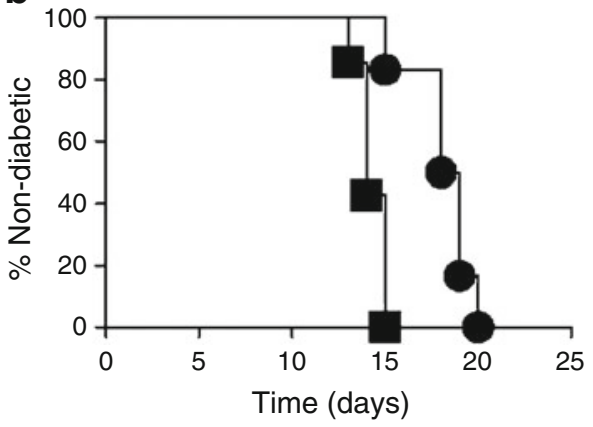

e Recipient mice

$\frac{(2 \text { months after transfer) }}{\text { NOD Scid NOD Scid }}$

$1 / 15^{-/-}$

(Diabetic)

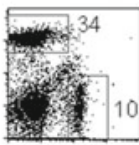

(Non-diabetic)
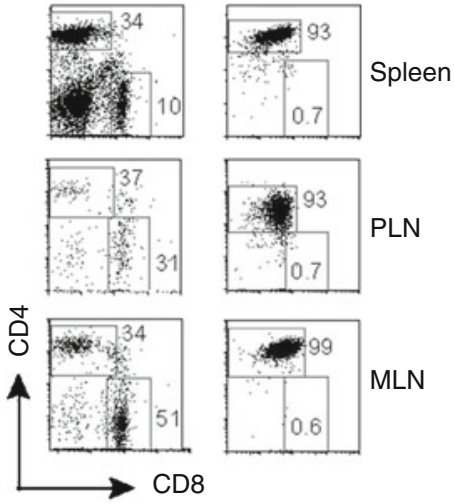

Fig. 5 IL-15 is required for the maintenance of diabetogenic CD8 $\mathrm{T}$ cells. (a) Splenocytes from diabetic 8.3-NOD mice expressing the transgenic 8.3 TCR were injected into NOD Scid (black circles, $n=6$ ), NOD Scid.Il15 $5^{-/}$(black square, $n=8$ ) and NOD Scid.gamma (white triangle, $n=4$ ) recipients in two separate experiments, and the recipients were monitored for diabetes. (b) Splenocytes from BDC2.5NOD mice expressing the MHC class-II restricted BDC2.5 transgenic TCR were injected into NOD Scid (circles, $n=5$ ) and NOD Scid.Ill $5^{-1-}$ (squares, $n=6$ ) mice in two separate experiments, and the recipients were monitored for diabetes. (c) Pooled lymph node cells from recipient mice recovered 1 month after transfer of splenocytes from diabetic 8.3-NOD donors were evaluated for the expression of CD4, CD8 and V $\beta 8.3$ TCR that detects the 8.3 transgenic TCR. Numbers in quadrants and square gates indicate the proportion of $\mathrm{CD} 4^{+}$and $\mathrm{CD} 8^{+} \mathrm{T}$ cells and 8.3 TCR transgenic $\mathrm{CD} 8^{+} \mathrm{T}$ cells. For comparison, the phenotype of

1 diabetes [36, 37]. Therefore, the resistance of NOD Scid.Il1 $5^{-1-}$ mice to developing diabetes is most likely to result from the lack of IL-15 required for the pathogenesis of type 1 diabetes rather than from the introduction of any potentially protective genes along with the $I l 15$ null allele originating from the $\mathrm{C} 57 \mathrm{BL} / 6$ strain.

Decreased incidence of diabetes in 8.3-NOD Scid.Il15 $5^{-/-}$ mice that express the highly pathogenic MHC class-Irestricted 8.3 TCR indicates that IL-15 is required for the cells from prediabetic 8.3-NOD mice is shown (first column). Representative data from more than five mice per group from at least two separate experiments are shown. (d) Total lymph node cells from representative mice in each group of recipients were labelled with CFSE and stimulated with IGRP peptide in the presence of irradiated NOD splenocytes, and cell proliferation was evaluated by flow cytometry on gated $\mathrm{CD} 8^{+} \mathrm{T}$ cells. Peaks from right to left represent successive cell division cycles, and the numbers denote the proportion of cells in each peak. Representative data from two similar experiments are shown. (e) In another group of recipient mice, the proportions of $\mathrm{CD} 4{ }^{+}$ and $\mathrm{CD} 8^{+} \mathrm{T}$ cells in spleen and pancreatic (PLN) and mesenteric (MLN) lymph nodes were evaluated 2 months after cell transfer. Representative data from at least four mice per group from two independent experiments are shown

initial activation of diabetogenic $\mathrm{CD} 8^{+} \mathrm{T}$ cells, independently of its known function of maintaining the memory $\mathrm{CD} 8^{+} \mathrm{T}$ cell pool $[11,24]$. IL-15 has been shown to stimulate the antigenpresenting functions of DCs and to induce production of IL-12 and type 1 IFNs $[3,38]$, which contribute to the pathogenesis of type 1 diabetes. Neutralisation of endogenous IL-12 in the NOD mouse has shown varying effects on the disease process [39], whereas blockade of IFN- $\alpha$ receptor signalling between 2 and 4 weeks of age was reported to profoundly diminish the 
Fig. 6 Inhibition of IL-15 signalling in NOD mice decreases type 1 diabetes. (a) Female NOD mice were administered, by i.p. injection, $200 \mu \mathrm{g}$ TM- $\beta 1 \mathrm{mAb}$ (white circles, $n=12$ ) or control $\mathrm{mAb}$ (black circles, $n=8$ ) three times a week for 4 weeks (indicated by the grey bar). Injected mice were followed for diabetes development up to 7 months of age. Data from mice from two different experiments were pooled. $p<0.01$ (logrank test). (b) At 7 months after $\mathrm{mAb}$ treatment, pancreatic sections from treated mice were scored for insulitis as detailed in Fig. 1b. Representative sections from each group of mice are shown
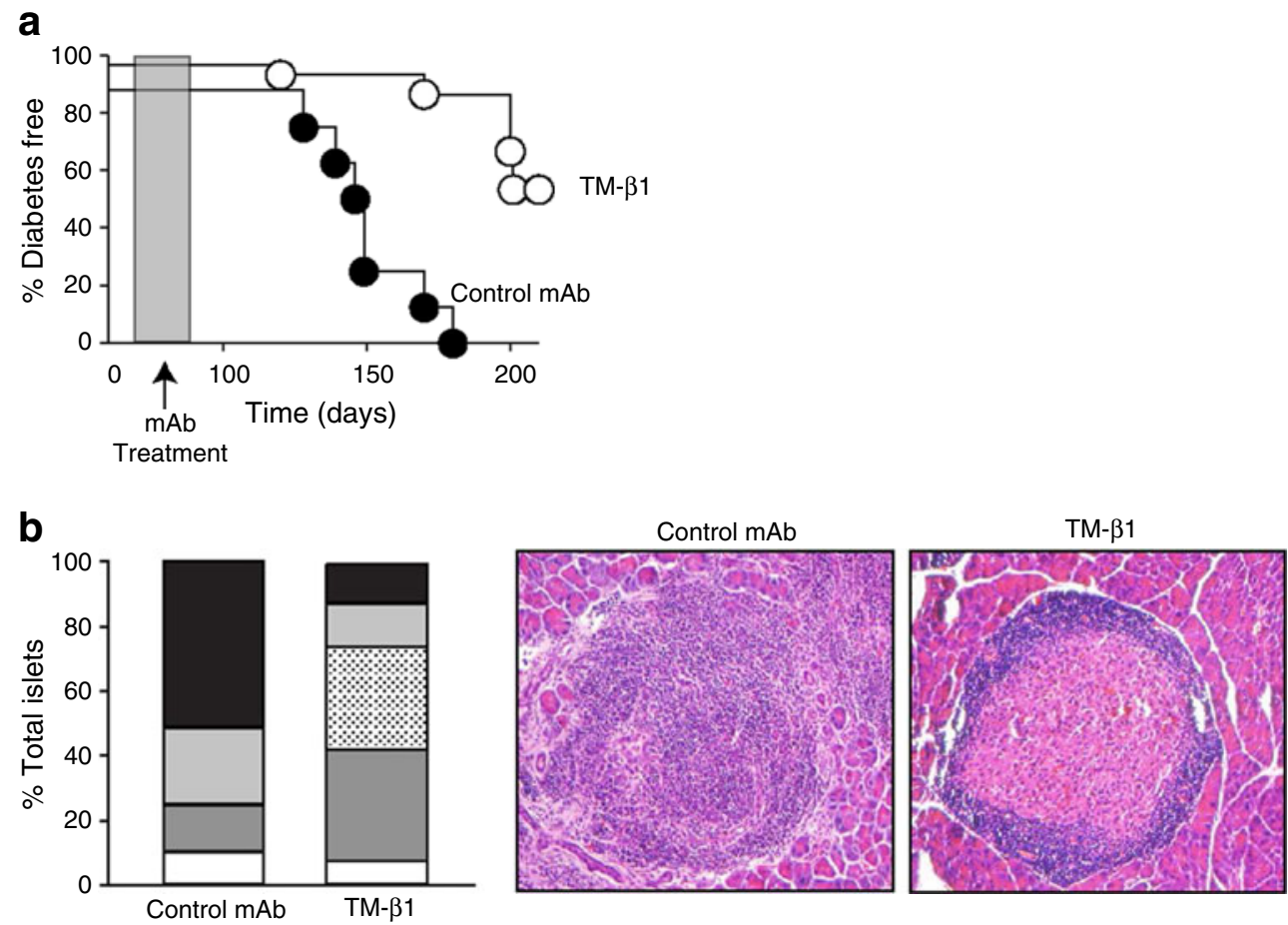

incidence of type 1 diabetes [40]. The latter study also identified plasmacytoid DCs as an important source of IFN- $\alpha$. Based on these findings, we speculate that the lower incidence and delayed onset of diabetes in NOD Scid.Ill15 $5^{-1-}$ and 8.3NOD Scid.Il15 $5^{-1-}$ mice could result from impaired antigen presentation and cytokine production by DCs within pancreatic islets and draining lymph nodes, leading to inefficient activation of autoreactive $\mathrm{CD} 8^{+} \mathrm{T}$ cells.

Prevention of type 1 diabetes by blocking IL-15 signalling at a stage when insulitis begins to appear also supports our contention that IL-15 promotes disease initiation. In the NOD mouse, DCs take up islet antigens released during islet remodelling at the time of weaning and present them to T cells in pancreatic lymph nodes [41]. The $\mathrm{CD} 8 \alpha^{+}$conventional DC subset (cDC), specialised in cross-presenting antigens to $\mathrm{CD}^{+} \mathrm{T}$ cells during the initiation of autoimmunity, is a major source of IL-15 [5]. As IL-15 signalling is required for survival and activation of DCs in vivo [4], it is possible that lack of IL-15 may compromise the antigen cross-presentation function of cDCs. Even though TM- $\beta 1 \mathrm{mAb}$ depletes NK cells transiently in vivo, this is an unlikely mechanism by which TM- $\beta 1$ confers protection from type 1 diabetes because NK cell depletion does not affect spontaneous diabetes development in NOD mice $[16,20]$. The protective effect of TM$\beta 1$ may result not only from inhibiting IL-15-dependent activation of DCs but also from blocking the stimulatory effect of IL- 15 on $\mathrm{CD}^{+} \mathrm{T}$ cell activation. We have recently shown that IL-15 enhances the antigen responsiveness of naive $\mathrm{CD} 8^{+}$ $\mathrm{T}$ cells in synergy with other inflammatory cytokines, such as IL-21, and that this process may play an important role in the activation of potentially autoreactive $\mathrm{CD} 8^{+} \mathrm{T}$ cells [18]. Accordingly, NOD mice that do not express IL-21 or IL-21R $\alpha$ do not develop diabetes [42, 43]. We have made similar findings on 8.3-NOD $I l 21^{-/-}$mice (Chen et al manuscript in preparation). In the NOD mouse model, IL-21 has been shown to act at the level of activation of $\mathrm{CD}^{+} \mathrm{T}$ cells as well as DCs $[44,45]$. Together, these observations suggest that IL-15 and IL-21, in addition to their effect on CD8 T cell homeostasis, can also play an important role in the initiation of the inflammatory response that leads to the eventual destruction of the islet. Hence, inhibition of the activity of IL-15 and/or IL-21 in the NOD mouse may prevent the efficient activation of diabetogenic $\mathrm{CD}^{+} \mathrm{T}$ cells both directly and indirectly via dampening the functions of APCs.

The inability of splenocytes from diabetic NOD mice to induce diabetes in NOD Scid.Il15 $5^{-/-}$mice (Fig. 3) suggests that IL-15 is continuously required for antigen-stimulated diabetogenic $\mathrm{T}$ cells to cause disease. While it is possible that the injected $\mathrm{T}$ cells may undergo reduced clonal expansion and/or develop less potent effector functions in the absence of IL-15, it is also likely that these cells do not receive adequate immunogenic stimuli due to compromised antigen presentation. We have presented evidence for both mechanisms. Diabetogenic $8.3 \mathrm{TCR}$ transgenic $\mathrm{CD} 8^{+} \mathrm{T}$ cells undergo gradual loss in NOD Scid.Il $15^{-1-}$ mice but not in NOD Scid.gamma mice where IL-15 is available (Fig. 5c). Although the lack of $\gamma_{\mathrm{c}}$ chain may affect signalling in DCs by several cytokines, including IL-4, IL-7, IL-15 and IL-21, only IL-15 is required for the survival and activation of DCs, whereas IL-7 and IL-21 are inhibitory [46] and IL-4 is a dispensable survival factor for 
DCs $[3-5,46]$. On the other hand, the donor $\mathrm{CD} 8^{+} \mathrm{T}$ cells, possessing intact IL-15R complex, can use IL-15 available in NOD Scid.gamma mice, which allows them to survive and cause disease upon subsequent transfer to NOD Scid mice, where IL-15 production and IL-15 signalling in APCs are intact. Hence, the inability of diabetogenic T cells to induce diabetes in NOD Scid.gamma mice is most likely to result from the failure of their APCs to use IL-15 and hence to activate $\mathrm{CD}^{+} \mathrm{T}$ cells. Other studies also support the requirement for IL-15 to sustain the pathogenic potential of autoreactive $\mathrm{CD}^{+} \mathrm{T}$ cells. Notably, neutralisation of IL-15 was shown to prevent autoreactive $\mathrm{CD} 8^{+} \mathrm{T}$ cells from causing skin lesions in a mouse model of graft-versus-host-like disease [47]. We have shown that IL-15 is necessary for $\mathrm{CD}^{+} \mathrm{T}$ cells stimulated suboptimally by cognate antigen or weak peptide agonists to induce disease in a TCR transgenic mouse model of autoimmune diabetes in the C57BL/6 background [18]. Collectively, IL-15 appears to promote the pathogenesis of type 1 diabetes at all stages of the disease, from the initiation of insulitis through to islet destruction.

The incidence of type 1 diabetes is increasing worldwide. Newly diagnosed type 1 diabetes patients still harbour a functional islet mass that is not sufficient to meet the body's insulin requirements. Current immune intervention strategies are therefore aimed at controlling the ongoing autoimmune responses against islet antigens to preserve the residual islet mass and facilitate their regeneration [48-50]. These strategies will also be useful to improve the survival of islet transplants without resorting to prolonged immunosuppressive regimens. In this context, significant reduction of diabetes incidence and disease severity in NOD mice lacking the $I l 15$ gene, and in NOD mice treated with anti-IL-15R $\beta \mathrm{mAb}$, indicates that IL-15 is a promising therapeutic target in type 1 diabetes. This approach may be combined with other immunotherapeutic strategies in the clinical management of type 1 diabetes patients.

Acknowledgements We thank Ms O. Borisovitch, Immunology Division, University of Sherbrooke, for genotyping the mice.

Funding This work was funded by JDRF Innovative award (no. 52010-608) and Canadian Institutes of Health Research operating grant (MOP-86530) to S. Ramanathan. Centre de Recherche Clinique Etienne-Le Bel is a research centre funded by the Fonds de la Recherché en Santé du Québec.

Duality of interest The authors declare that there is no duality of interest associated with this manuscript.

Contribution statement SR, SI, YGC, CL, MM, JS, TT, XLC and DB planned the experiments. DB and XLC carried out the experiments. CL, MM and SR generated, monitored and analysed data on the development of diabetes. JS and TT provided reagents and expertise. All the authors contributed to writing and revising the intellectual content of the manuscript. All authors have approved the final version of the manuscript.

\section{References}

1. Fehniger TA, Caligiuri MA (2001) Interleukin 15: biology and relevance to human disease. Blood 97:14-32

2. Waldmann TA, Tagaya Y (1999) The multifaceted regulation of interleukin-15 expression and the role of this cytokine in NK cell differentiation and host response to intracellular pathogens. Annu Rev Immunol 17:19-49

3. Ohteki T, Suzue K, Maki C, Ota T, Koyasu S (2001) Critical role of IL-15-IL-15R for antigen-presenting cell functions in the innate immune response. Nat Immunol 2:1138-1143

4. Dubois SP, Waldmann TA, Muller JR (2005) Survival adjustment of mature dendritic cells by IL-15. Proc Natl Acad Sci U S A 102:8662-8667

5. Ohteki T, Tada H, Ishida K et al (2006) Essential roles of DCderived IL-15 as a mediator of inflammatory responses in vivo. J Exp Med 203:2329-2338

6. Ruckert R, Brandt K, Bulanova E, Mirghomizadeh F, Paus R, Bulfone-Paus S (2003) Dendritic cell-derived IL-15 controls the induction of $\mathrm{CD} 8 \mathrm{~T}$ cell immune responses. Eur J Immunol 33:3493-3503

7. McInnes IB, al-Mughales J, Field M et al (1996) The role of interleukin-15 in $\mathrm{T}$ cell migration and activation in rheumatoid arthritis. Nat Med 2:175-182

8. Meresse B, Chen Z, Ciszewski C et al (2004) Coordinated induction by IL15 of a TCR-independent NKG2D signaling pathway converts CTL into lymphokine-activated killer cells in celiac disease. Immunity 21:357-366

9. Signore A, Annovazzi A, Giacalone P et al (2003) Reduced cumulative incidence of diabetes but not insulitis following administration of chimeric human IL-15-murine IgG2b in NOD mice. Diabetes Metabol Res Rev 19:464-468

10. Xia J, Liu W, Hu B, Tian Z, Yang Y (2010) IL-15 promotes regulatory $\mathrm{T}$ cell function and protects against diabetes development in NK-depleted NOD mice. Clin Immunol 134:130-139

11. Kennedy MK, Glaccum M, Brown SN et al (2000) Reversible defects in natural killer and memory CD8 $\mathrm{T}$ cell lineages in interleukin 15-deficient mice. J Exp Med 191:771-780

12. Carnaud C, Gombert J, Donnars O, Garchon H, Herbelin A (2001) Protection against diabetes and improved NK/NKT cell performance in NOD.NK1.1 mice congenic at the NK complex. J Immunol 166:2404-2411

13. Sharif S, Arreaza GA, Zucker P et al (2001) Activation of natural killer $\mathrm{T}$ cells by alpha-galactosylceramide treatment prevents the onset and recurrence of autoimmune type 1 diabetes. Nat Med 7:1057-1062

14. Alba A, Planas R, Clemente X et al (2008) Natural killer cells are required for accelerated type 1 diabetes driven by interferon-beta. Clin Exp Immunol 151:467-475

15. Angstetra E, Graham KL, Zhao Y et al (2012) An indirect role for NK cells in a CD4(+) T cell-dependent mouse model of type I diabetes. Immunol Cell Biol 90:243-247

16. Poirot L, Benoist C, Mathis D (2004) Natural killer cells distinguish innocuous and destructive forms of pancreatic islet autoimmunity. Proc Natl Acad Sci U S A 101:8102-8107

17. Koulmanda M, Budo E, Bonner-Weir S et al (2007) Modification of adverse inflammation is required to cure new-onset type 1 diabetic hosts. Proc Natl Acad Sci U S A 104:13074-13079

18. Ramanathan S, Dubois S, Chen XL, Leblanc C, Ohashi PS, Ilangumaran S (2011) Exposure to IL-15 and IL-21 enables autoreactive CD8 $\mathrm{T}$ cells to respond to weak antigens and cause disease in a mouse model of autoimmune diabetes. J Immunol 186:5131-5141

19. Li DS, Yuan YH, Tu HJ, Liang QL, Dai LJ (2009) A protocol for islet isolation from mouse pancreas. Nat Protoc 4:1649-1652 
20. Tanaka T, Kitamura F, Nagasaka Y, Kuida K, Suwa H, Miyasaka M (1993) Selective long-term elimination of natural killer cells in vivo by an anti-interleukin 2 receptor beta chain monoclonal antibody in mice. J Exp Med 178:1103-1107

21. Verdaguer J, Schmidt D, Amrani A, Anderson B, Averill N, Santamaria P (1997) Spontaneous autoimmune diabetes in monoclonal T cell nonobese diabetic mice. J Exp Med 186:1663-1676

22. Lieberman SM, Evans AM, Han B et al (2003) Identification of the beta cell antigen targeted by a prevalent population of pathogenic CD8+ T cells in autoimmune diabetes. Proc Natl Acad Sci U S A 100:8384-8388

23. Trudeau JD, Kelly-Smith C, Verchere CB et al (2003) Prediction of spontaneous autoimmune diabetes in NOD mice by quantification of autoreactive T cells in peripheral blood. J Clin Invest 111:217-223

24. Lodolce JP, Boone DL, Chai S et al (1998) IL-15 receptor maintains lymphoid homeostasis by supporting lymphocyte homing and proliferation. Immunity 9:669-676

25. Nakamura M, Asao H, Takeshita T, Sugamura K (1993) Interleukin-2 receptor heterotrimer complex and intracellular signaling. Semin Immunol 5:309-317

26. Francois C, Dantal J, Sorel M et al (1996) Antibodies directed at mouse IL-2-R alpha and beta chains act in synergy to abolish T cell proliferation in vitro and delayed type hypersensitivity reaction in vivo. Transpl Int 9:46-50

27. Yokoyama S, Watanabe N, Sato N et al (2009) Antibody-mediated blockade of IL-15 reverses the autoimmune intestinal damage in transgenic mice that overexpress IL-15 in enterocytes. Proc Natl Acad Sci U S A 106:15849-15854

28. Mathews CE, Graser RT, Bagley RJ et al (2003) Genetic analysis of resistance to Type-1 Diabetes in ALR/Lt mice, a NOD-related strain with defenses against autoimmune-mediated diabetogenic stress. Immunogenetics 55:491-496

29. Leiter EH, Reifsnyder PC, Wallace R, Li R, King B, Churchill GC (2009) NOD $\times 129$.H2(g7) backcross delineates 129S1/SvImJ-derived genomic regions modulating type 1 diabetes development in mice. Diabetes 58:1700-1703

30. Wicker LS, Todd JA, Prins JB, Podolin PL, Renjilian RJ, Peterson LB (1994) Resistance alleles at two non-major histocompatibility complex-linked insulin-dependent diabetes loci on chromosome 3, Idd3 and Idd10, protect nonobese diabetic mice from diabetes. J Exp Med 180:1705-1713

31. Cornelius JG, Luttge BG, Peck AB (1993) Antioxidant enzyme activities in IDD-prone and IDD-resistant mice: a comparative study. Free Radic Biol Med 14:409-420

32. Cao X, Shores EW, Hu-Li J et al (1995) Defective lymphoid development in mice lacking expression of the common cytokine receptor gamma chain. Immunity 2:223-238

33. Andre-Schmutz I, Hindelang C, Benoist C, Mathis D (1999) Cellular and molecular changes accompanying the progression from insulitis to diabetes. Eur J Immunol 29:245-255

34. Mathews CE, Suarez-Pinzon WL, Baust JJ, Strynadka K, Leiter EH, Rabinovitch A (2005) Mechanisms underlying resistance of pancreatic islets from ALR/Lt mice to cytokine-induced destruction. J Immunol 175:1248-1256
35. Suwanai H, Wilcox MA, Mathis D, Benoist C (2010) A defective I115 allele underlies the deficiency in natural killer cell activity in nonobese diabetic mice. Proc Natl Acad Sci U S A 107:9305-9310

36. Rothe H, Hausmann A, Kolb H (2002) Immunoregulation during disease progression in prediabetic NOD mice: inverse expression of arginase and prostaglandin $\mathrm{H}$ synthase 2 vs. interleukin- 15 . Horm Metab Res 34:7-12

37. Cardozo AK, Proost P, Gysemans C, Chen MC, Mathieu C, Eizirik DL (2003) IL-1beta and IFN-gamma induce the expression of diverse chemokines and IL-15 in human and rat pancreatic islet cells, and in islets from pre-diabetic NOD mice. Diabetologia 46:255-266

38. Gary-Gouy H, Lebon P, Dalloul AH (2002) Type I interferon production by plasmacytoid dendritic cells and monocytes is triggered by viruses, but the level of production is controlled by distinct cytokines. J Interferon Cytokine Res 22:653-659

39. Fujihira K, Nagata M, Moriyama H et al (2000) Suppression and acceleration of autoimmune diabetes by neutralization of endogenous interleukin-12 in NOD mice. Diabetes 49:1998-2006

40. Li Q, McDevitt HO (2011) The role of interferon alpha in initiation of type I diabetes in the NOD mouse. Clin Immunol 140:3-7

41. Hoglund P, Mintern J, Waltzinger C, Heath W, Benoist C, Mathis D (1999) Initiation of autoimmune diabetes by developmentally regulated presentation of islet cell antigens in the pancreatic lymph nodes. J Exp Med 189:331-339

42. McGuire HM, Walters S, Vogelzang A et al (2011) Interleukin-21 is critically required in autoimmune and allogeneic responses to islet tissue in murine models. Diabetes 60:867-875

43. Spolski R, Kashyap M, Robinson C, Yu Z, Leonard WJ (2008) IL21 signaling is critical for the development of type I diabetes in the NOD mouse. Proc Natl Acad Sci U S A 105:14028-14033

44. McGuire HM, Vogelzang A, Ma CS et al (2011) A subset of interleukin-21+ chemokine receptor CCR9+ T helper cells target accessory organs of the digestive system in autoimmunity. Immunity 34:602-615

45. Van Belle TL, Nierkens S, Arens R, von Herrath MG (2012) Interleukin-21 receptor-mediated signals control autoreactive $\mathrm{T}$ cell infiltration in pancreatic islets. Immunity 34:1060-1072

46. Rochman Y, Spolski R, Leonard WJ (2009) New insights into the regulation of $\mathrm{T}$ cells by gamma(c) family cytokines. Nat Rev Immunol 9:480-490

47. Miyagawa F, Tagaya Y, Kim BS et al (2008) IL-15 serves as a costimulator in determining the activity of autoreactive CD8 $\mathrm{T}$ cells in an experimental mouse model of graft-versus-host-like disease. J Immunol 181:1109-1119

48. Goodyear M (2006) Learning from the TGN1412 trial. BMJ 332:677-678

49. Mathieu C, Gillard P (2011) Arresting type 1 diabetes after diagnosis: GAD is not enough. Lancet 378:291-292

50. Wherrett DK, Bundy B, Becker DJ et al (2011) Antigen-based therapy with glutamic acid decarboxylase (GAD) vaccine in patients with recent-onset type 1 diabetes: a randomised doubleblind trial. Lancet 378:319-327 